Document downloaded from:

http://hdl.handle.net/10251/66544

This paper must be cited as:

Doménech Antich, EM.; Amorós, J.; Pérez Gonzalvo, M.; Escriche Roberto, MI. (2011). Implementation and effectiveness of the HACCP and pre-requisites in food establishments. Food Control. 22(8):1419-1423. doi:10.1016/j.foodcont.2011.03.001.

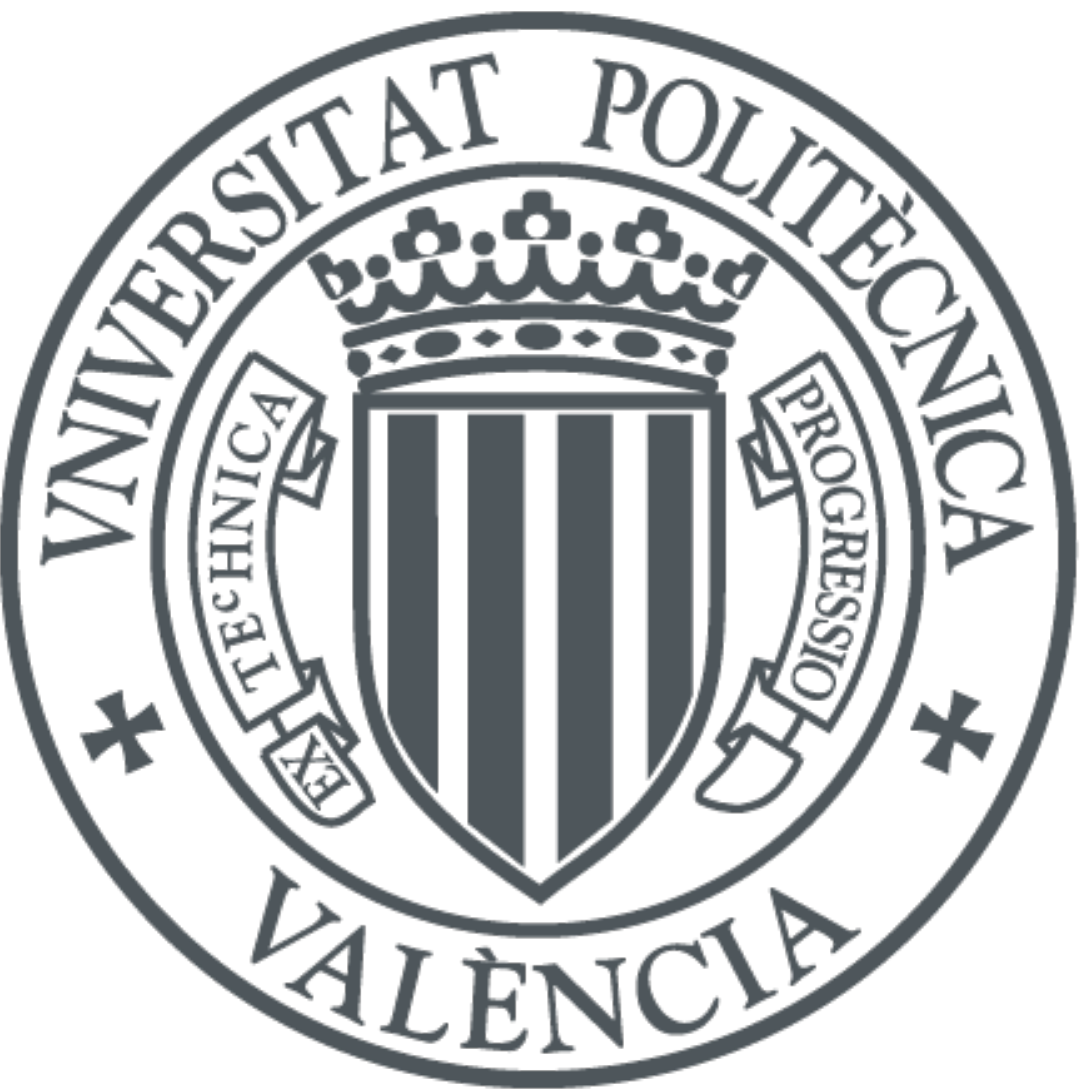

The final publication is available at

https://dx.doi.org/10.1016/j.foodcont.2011.03.001

Copyright Elsevier

Additional Information 


\title{
Implementation and effectiveness of the HACCP and Prerequisites in Food establishments
}

\author{
E. Doménech ${ }^{\text {a, }}{ }^{*}$, J.A. Amorós ${ }^{b}$, M. Pérez-Gonzalvo ${ }^{c}$, I. Escriche $^{\text {a }}$ \\ a Departamento de Tecnología de Alimentos, Instituto de Ingeniería de Alimentos para el Desarrollo. \\ Universidad Politécnica de Valencia, Camino de Vera 14, 46022 Valencia, Spain \\ b Area de Investigación en Seguridad Alimentaria. Centro Superior de Investigación en Salud Pública \\ (CSISP). Valencia \\ ${ }^{\mathrm{c}}$ Centro de Salud Pública de Xativa. Conselleria de Sanitat. Generalitat Valenciana, Spain
}

\begin{abstract}
The aim of this paper was to identify the most important weaknesses in the implementation and effectiveness of the prerequisites and HACCP found in food establishments. To cover these objectives, official control audits of the manuals and their implementation in 1350 small and 66 medium size organizations: restaurants, hotels and cafeterias in one area of the Valencian region (Spain) were carried out from 2007 to 2010. The microbiological quality of 1054 ready-to-consume dishes was also evaluated as an indicator of the effectiveness of the control at Critical Control Points. The results showed that the main deficiencies in the implementation of the prerequisites and HACCP were found in conditions and structural design followed by hygiene \& cleaning. Moreover, the analysis of L. monocytogenes in dishes at the time of consumption shows that $99.6 \%$ were of good microbiological quality. This indicates that in relation to this hazard, the implementation of safety management systems in the majority of the food establishments was effective. These results demonstrate the crucial role played by official control to ensure the welfare of consumers and how it facilitates continuous improvement in the safety management of these businesses.
\end{abstract}

Key words: Safety management, Prevalence, Listeria monocytogenes, Official control.

\section{$1 \quad$ Introduction}

The food policy of the European Union is based on high food safety standards that can be used to protect the health of consumers. As a result of this priority, the EU designed a new concept of food regulation, which culminated in the White Paper on Food Safety. This describes a set of actions required to complete and modernize the law of the European Union in the scope of food and nutrition. Food safety is organized in a coordinated and integrated manner, taking into consideration all aspects, from primary production to the consumer (EPC, 2004).

During the past decade, there was an increasing interest in developing tools to link the requirements of food safety programs with their expected public health impact. Food safety management systems such as pre-requisites like: good hygiene and manufacturing practices, appropriate cleaning, sanitation programs, or the HACCP plan are required by the administration for the prevention or inhibition of the growth of pathogens (van Schothorst et al, 2009; Gorris, 2005). Nowadays, quality assurance standards and guidelines are widely applied in the food industry, however their application in food establishments such as restaurants, hotels and cafeterias still lags behind (Effler et al, 2001; Olsen et al., 2000; Hughes et al., 2007). This may be due to there being important differences between the food industry and food 
establishments, at the level of organization (staff training, structure and size) technology (capacity for analysis, level of automation, facilities) and production (number of products per batch, raw materials, elaboration processes, and time to serve the product).

Nowadays, the administration plays a fundamental role in ensuring food safety through official controls. In fact, it makes routine official inspections in order to check the level of implementation of prerequisites and the HACCP Plan and, analyzes final products as indicators to verify the effectiveness of the management system.

This paper shows the results obtained by the official control carried out by the Valencian administration in small and medium size food establishments in the Onteniente and Xativa area (Valencian region, Spain) in the period between 2007 and 2010. The main objective was to identify the primary weaknesses in the implementation of the prerequisites and $\mathrm{HACCP}$ and evaluate their effectiveness in this kind of establishment in the studied area.

\section{$2 \quad$ Materials and methods}

\subsection{Items checked}

The geographic scope of this research is limited to health department-14 Xativa/Ontinyente that covers 64 municipalities in the Valencian region (Spain). The analyzed data correspond to official inspections made from 2007 to 2009. The type of inspection carried out by the Administration depends on the size of the company. Food establishments are classified as Small companies (employing less than 3 workers) or Medium companies (with more than 3 and less than 9). Every year, approximately 1350 Small and 66 Medium companies were surveyed, all of them, subject to monitoring and food control by the Public Administration. In all companies the level of compliance of prerequisites and HACCP were checked considering the following items:

- Food handling. Training and personal hygiene practices must be observed, and legal requirements must be fulfilled.

- Hygiene and Cleaning: The conditions of cleanliness and sanitation of the equipment and supplies. Any failure to comply with the Cleaning and Disinfection Plan is considered a non-conformity.

- Pest control. Regulation or management of any species perceived to be detrimental to food safety. Conditions of application of pest control procedures should be considered by the companies. For example, a non-conformity will arise when there are no effective measures to combat pests, or they are installed in places that could be considered a hazard to food or staff safety.

- Storage: The conditions under which raw materials, ingredients and products are stored as well as everything related to the packing used in the establishment. A nonconformity is considered, for example, when containers are exposed to the elements or they are near sources of pollution.

- Structure and Design. Design of the food industry plant and equipment in a way that hygienic conditions are safeguarded. A proximity to pollution sources as well as an unsatisfactory maintenance of industrial facilities such as floors, walls, roofs, gutters, doors and windows will be considered non-conformities.

- Traceability. Proper tracking of raw materials and products, both forwards and backwards.

- Waste control. Ability of the company for the storage and management of its industrial waste. A non-conformity will arise when, the storage of waste is done in such a way 
as to cause: spread of odours, attraction of insects or contamination of other products or surfaces that come into contact with food. Deviations of the Waste Plan or ineffectiveness and incompleteness of the former are considered nonconformities as well.

- Water supply. Quality of water must be ensured, above all if it comes into contact with the food processing.

- Labelling. Correct labelling of the product in accordance with general and specific legal requirements.

- Processing. Control of the whole production process: Reception of raw materials, processing transactions and handling practices (with emphasis on heat treatment and cooling), wrapping and packaging, including the supervision of each control parameter and its respective measure.

- Transportation. Everything related to transport will be assessed: Vehicle conditions, hygiene and cleaning of the devices, thermal control, and unloading conditions.

\subsection{Non-conformities}

The non-conformities or deficiencies observed were classified into three types according to their severity:

- Type I. Deficiencies that involve a minor failure to comply with the rules, but that do not affect the safety of the product.

- Type II. Deficiencies that involve the failure to comply with the rules, and could affect the safety of the product.

- Type III. Deficiencies that involve the failure to comply with the rules, and definitely affect the safety of the product.

\subsection{Samples collection}

A total of 1054 dishes were analyzed:

a) Meat (814 samples) divided into two groups, as shown in Table 1. (I) Minced meat (226 samples): Grilled hamburgers and meat balls with sauce and (ii) Nonminced meat (588 samples). Within this group, three types of meat have been identified: chicken (e.g. grilled chicken breast, curried chicken drumsticks, chicken with sauce, etc.) beef (e.g. steak and grilled sirloin steak, beef stew, etc.) and pork (e.g. grilled tenderloin, barbecued ribs, sirloin with sauce, etc.). Taking into account the type of cooking, the percentage according to the type of meat, in sauce (i.e. $65 \%$ chicken, beef $84 \%$ pork $65 \%$ ) and grilled (i.e. $35 \%$ chicken, beef $16 \%$ pork $28 \%$ ). b) Fish (247 samples): hake, panga, cod, monkfish, squid, tuna, gilthead, swordfish and sole. Approximately 50\% of the fish dishes were prepared for frying and $50 \%$ in sauce. Samples were taken and analyzed by the Department of Health and Food Control Service under the official control collected by the sampling plan (Regulation (EC) $2073 / 2005$ of 15 November 2005).

Approximately $250 \mathrm{~g}$ of the ready-toserve dishes was sampled. They were immediately stored in insulated containers at $4^{\circ} \mathrm{C}$ and sent to the laboratory for analysis. The transport time was no more than one hour in any case. A record of the name of the company, the batch, expiry date, date of manufacture, storage conditions, etc., was generated in each case.

\subsection{Sample examination}

Samples were examined by official control laboratories, which are accredited by ENAC (the body designated by the Spanish Government to assess technical competence in accordance with international standards) following the standard ISO/IEC 17025: 2005 which describes the general requirements for the competence of testing and calibration laboratories. 
The detection of pathogens was performed following NF EN ISO 112901 and was counted using NF EN ISO 11290-2. This method involves two selective enrichments in Fraser half and Fraser broth (Biomerieux, Marcy L'Etoile, France). Presence/absence testing of L. monocytogenes in $25 \mathrm{~g}$ was performed using the AFNOR validated VIDAS LMO2 method (LMO2; bioMerieux, Inc., Durham, NC), an enzyme linked fluorescent assay (ELFA) (Biomérieux, Marcy-l'Etoile, France). A positive result must be confirmed following the standard plating procedures using the remaining broth stored at $2-8^{\circ} \mathrm{C}$.

If results were positive an isolate from Fraser broth and ALOA agar was made, and then the confirmation was made with the ADN AccuProbe L. monocytogenes culture identification test (bioMérieux ref. 39500/Gen-Probe Cat. No. 2920).

Microbiological results were
interpreted in accordance with microbiological criteria of the official control according to the indications of the Commission Regulation (EC) No 2073/2005). These criteria use the level of bacterial contamination as an indicator of food safety, and classify foods with a L. monocytogenes count of $100 \mathrm{CFU} / \mathrm{g}$ or more for ready-to-eat food placed on the market during their shelf life as legally unsatisfactory.

\subsection{Statistical analysis}

Descriptive and statistical analyses of the data were undertaken using Statgraphics 5.0. Relative proportions were compared using the Chi-squared test $\left(X^{2}\right)$ and Fisher's exact test. A probability value of less than $5 \%$ was deemed to be significant.

\section{$3 \quad$ Results and discussion}

\subsection{Non conformities}

Fig. 1 shows the percentage of nonconformities of type I, II and III that were found in food establishments. Taking into account the severities of the non-conformities, it is important to emphasize that type I non-conformities, which in any case involve a hazard to consumer safety, are more common in small companies (91\%) than in medium ones $(85 \%)$. Type II are less frequent ( $9 \%$ and $14 \%$ respectively) and type III non-conformities, very serious faults, are practically nonexistent, not exceeding $1 \%$ in the medium and small companies.

Fig. 2 shows the level of compliance of the different items checked in the companies inspected by the administration, specifying in each case the size of the food establishments studied. In medium companies, as well as in the small ones, "transportation" is the item with the lowest number of nonconformities, followed by "labelling" and "storage" in medium establishments and "water" and "traceability" in the small ones. On the other hand, the items with most non-conformities for both types of companies were "structure \& design" followed by "hygiene \& cleaning". These results coincide with several studies that conclude that the weak points in food establishments are: contaminated supplies, dirty food contact surfaces, poor personnel hygiene practices, inappropriate storage temperatures, and insufficient cooking (Käferstein, 2003; Fuster-Valls et al., 2008; Jones et al., 2008).

\subsection{Food management system effectiveness}

The food establishment sector is one of the main sources of listeria outbreaks in industrialized countries (EFSA, 2007). Over the last two decades, numerous foodborne cases and outbreaks of human listeriosis have been traced to meat, fish and seafood products, with evidence of transmission through consumption of these products (Selby et al., 2006). 
To evaluate the effectiveness of the actual food management systems (prerequisites and HACCP), the official control evaluates the microbiological performance focus on L. monocytogenes in 1054 end products belonging to meat and fish sectors as an indicator of good implementation. Significant differences ( $p$-value 0.0000) were found between the prevalence of $L$. monocytogenes with respect the groups of dishes (meat and fish).

\subsubsection{Microbiological quality of meat}

a) Microbiological quality of minced meat

L. monocytogenes was present in 58 of the 114 samples of meat balls and 53 of 112 hamburgers which represent $50.88 \%$ and $47.32 \%$ respectively, (Table 1). Nevertheless, microbiological quality was acceptable in all cases, since the load at the time of consumption was less than $100 \mathrm{CFU} / \mathrm{g}$. Selby et al., 2006 found $42 \%$ of prevalence of L. monocytogenes in pork products; however, the positive samples contained less than $10^{2} \mathrm{CFU} / \mathrm{g}$ in all cases. De Simón \& Ferrer, 1998, also observed that in prevalence cases of L. monocytogenes the counts in meat products are usually low, less than $10^{2}$ $\mathrm{CFU} / \mathrm{g}$. Considering the percentage of prevalence with respect to the type of dishes belonging to the minced meat group no significant differences ( $p$ value $=0.0522$ ) were found. This high percentage of the presence of this microorganism in the ready-to-serve product may be due to two causes: A possible recontamination due to incurred handling and storage, as has been reflected in the previous paragraph concerning non-conformities, and undercooking. Passos \& Kuaye, 2002 revealed that control of the cooking process by the final internal temperature of hamburgers can be insufficient to ensure a safe product due to a wide variability that can occur in the internal temperature at the end of cooking.

b) Microbiological quality of non minced meat

A total of 588 samples of meat dishes were analyzed. Pork is the type of meat with the highest percentage of absence (74.14\%), followed by chicken $(73.40 \%)$ and beef (70.53\%), however differences between the different types of meat in relation to prevalence of $L$. monocytogenes were not significant ( $\mathrm{p}$ value $=0.7939)$

Microbiological quality criteria were acceptable in all cases $(\leq 100 \mathrm{CFU} / \mathrm{g})$, except in 4 samples of stewed pork (i.e. 15000; 7700, 7000 \& 5900 CFU/g), (Table 1). Taking into account the type of preparation, significant differences were observed $(p$-value $=0.0337)$. In fact, in beef and pork there is a higher prevalence rate in the samples that were cooked with sauce $(33.8 \%$ and $27.9 \%$ respectively) than for those that were grilled (6.7\% and $21 \%$ respectively). In chicken, $22.7 \%$ of prevalence of $L$. monocytogenes was found in samples that were cooked with sauce and $33.3 \%$ of the samples that were grilled. The prevalence in grilled samples is associated with inadequate heat treatment (Passos \& Kuay, 2002), while the prevalence in meat that was cooked with sauce, whose cooking time is greater, is associated with poor maintenance or inadequate reheating. Fenlon et al., 1996, observed that the prevalence of Listeria spp. in meat and meat products may be attributed either to improper hygienic practice during processing or to food handlers.

\subsubsection{Microbiological quality of fish}

A total of 247 samples of fish were analyzed. The prevalence was very different between the types of fish. The minimum value was $14.29 \%$ in swordfish and $57.69 \%$ in monkfish. 
Nevertheless, the positive cases did not in any case reach a load of $100 \mathrm{CFU} / \mathrm{g}$ and the microbiological quality was considered acceptable in all cases. The results show that a significant difference $(p$ value $=0.0000)$ existed between the type of fish and the percentage of prevalence $L$. monocytogenes.

With respect to the type of cooking (in sauce or fried) non significant differences were observed ( $p$-value= 0.6233). Parihar, et al., 2008 highlight that $L$. monocytogenes is not usually found in fish; however, insanitary conditions of food contact surfaces, and handling areas and personal hygiene practices could increase potential contamination by this microorganism. De Simon \& Ferrer, 1998, who analyzed foods purchased in restaurants and delicatessens, found that the prevalence of L. monocytogenes in seafood dishes was $1.4 \%$, where two samples had a load less than $100 \mathrm{CFU} / \mathrm{g}$ and 1 sample more than $1000 \mathrm{CFU} / \mathrm{g}$.

\section{Conclusions}

Food Establishments had a good level of self-control and the most serious nonconformities (those that definitely affect the safety of the product) are practically nonexistent. The information provided by the official inspection audits clearly reveals the main weaknesses in the implementation of the food safety management system. In fact, Structure \& Design followed by Hygiene \& Cleaning were the most frequent non-conformities detected in the majority of the companies, regardless of size. Moreover, $99.6 \%$ of the dishes analyzed had an acceptable microbiological quality with respect to L. monocytogenes. These results indicate a good level of implementation and effectiveness of prerequisites and HACCP in most establishments that were examined.

This study highlights the role of official control, in the framework of the food chain, to ensure the welfare of consumers and to support the management of small and medium size food establishments in order to continuously improve their system of food safety management.

\section{References}

De Simón, M., \& Ferrer, M. D. (1998). Initial numbers, serovars and phagevars of Listeria monocytogenes isolated in prepared foods in the city of Barcelona (Spain). International Journal of Food Microbiology, 44(1), 141144.

Effler, P., Ieong, M-C., Kimura, A., Nakata, M., Burr, R., Cremer, E., \& Slutsker, L. (2001). Sporadic Campylobacter jejuni infections in Hawaii: associations with prior antibiotic use and commercially prepared chicken. The Journal of Infectious Diseases, 183, 11521155.

EFSA (2007). European Food Safety Authority. Scientific Opinion of the Panel on Biological Hazards on a request from the European Commission on Request for updating the former SCVPH opinion on Listeria monocytogenes risk related to ready to eat foods and scientific advice on different levels of Listeria monocytogenes in ready-to-eat foods and the related risk for human illness. The EFSA Journal 599, 1-42.

EPC (2004). Regulation No. 852/2004 of the European Parliament and of the Council of 29 April 2004 on the hygiene of foodstuffs. Official Journal, L 139, 30/04/2004, 00010054 http://www.food.gov.uk/ multimedia/pdfs/h3ojregulation.pdf.

Fenlon, D.R., Wilson, J., Donachie, W. (1996). The incidence and level of Listeria monocytogenes contamination of food sources at primary production and initial processing. Journal of Applied Bacteriology, 81, 641-650.

Fuster-Valls, N., Hernandez-Herrero, M., Marinde-Mateo, M., \& Rodriguez-Jerez, J.J. (2008). Effect of different environmental conditions on the bacteria survival on stainless steel surfaces. Food Control, 19, 308-314.

Gorris, L.G.M. (2005). Food safety objective: An integral part of food chain management. Food Control, 16, (9), 801-809.

Hughes, C., Gillespie, I., \& O’Brien, S. (2007). Foodborne transmission of infectious intestinal disease in England and Wales, 1992-2003. Food Control, 18 (7), 766-722. 
Jones, S.L., Parry, S.M., O'Brien, S.J., \& Palmer, S.R. (2008). Are staff Management practices and inspection risk ratings associated with foodborne disease outbreaks in the catering industry in England and Wales? Journal of Food Protection, 71 (3), 550-557.

Käferstein, F. (2003) Actions to reverse the upward curve of foodborne illness. Food Control, 14 (2), 101-109.

Olsen, S., MacKinon, L., Goulding, J., Bean, N. \& Slutsker, L., (2000). Surveillance for foodborne disease outbreaks- United States, 1993-1997. Morbidity and Mortality Weekly Report, 49, 1-51.

Parihar, V.S., Barbuddhe, S.B., DanielssonTham, M.L. \& Tham, W. (2008). Isolation and characterization of Listeria species from tropical seafoods. Food Control, 19, (6), 566569.

Passos, M.H.C.R., \& Kuaye, A.Y. (2002). Influence of the formulation, cooking time and final internal temperature of beef hamburgers on the destruction of Listeria monocytogenes. Food control, 13 (1), 33-40.

Regulation (EC) No 2073/2005 of 15 November 2005 on microbiological criteria for foodstuffs Official Journal L 338 , 22/12/2005 P. 0001 - 0026

Selby, T.L., Berzins, A., Gerrard, D.E., Corvalan, C.M., Grant, A.L., \& Linton, R.H. (2006). Microbial heat resistance of Listeria monocytogenes and the impact on ready-toeat meat quality after post-package pasteurization. Meat Science, 74, (3), 425434.

Van Schothorst, M., Zwietering, M.H. Ross T., Buchanan, R.L., \& Cole, M.B. (2009) Relating microbiological criteria to food safety objectives and performance objectives. Food Control, 20(11), 967-979.

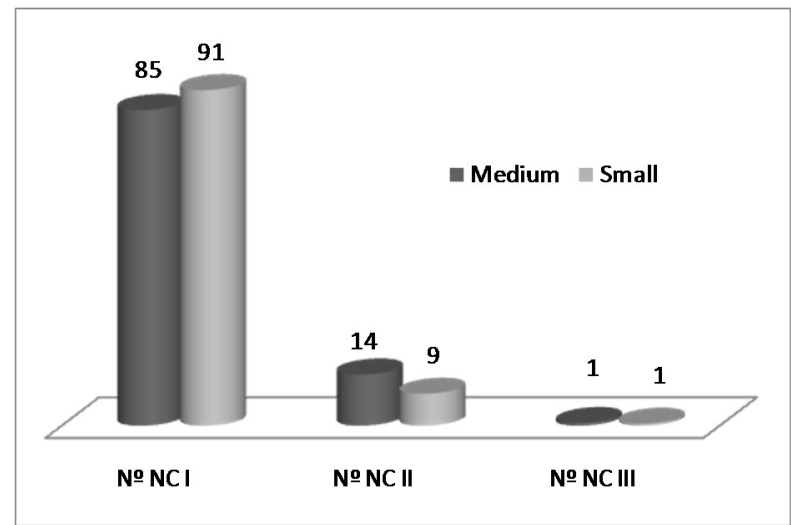

Fig. 1. Percentage of non-conformities of type I, II and III that were found in medium and small companies 


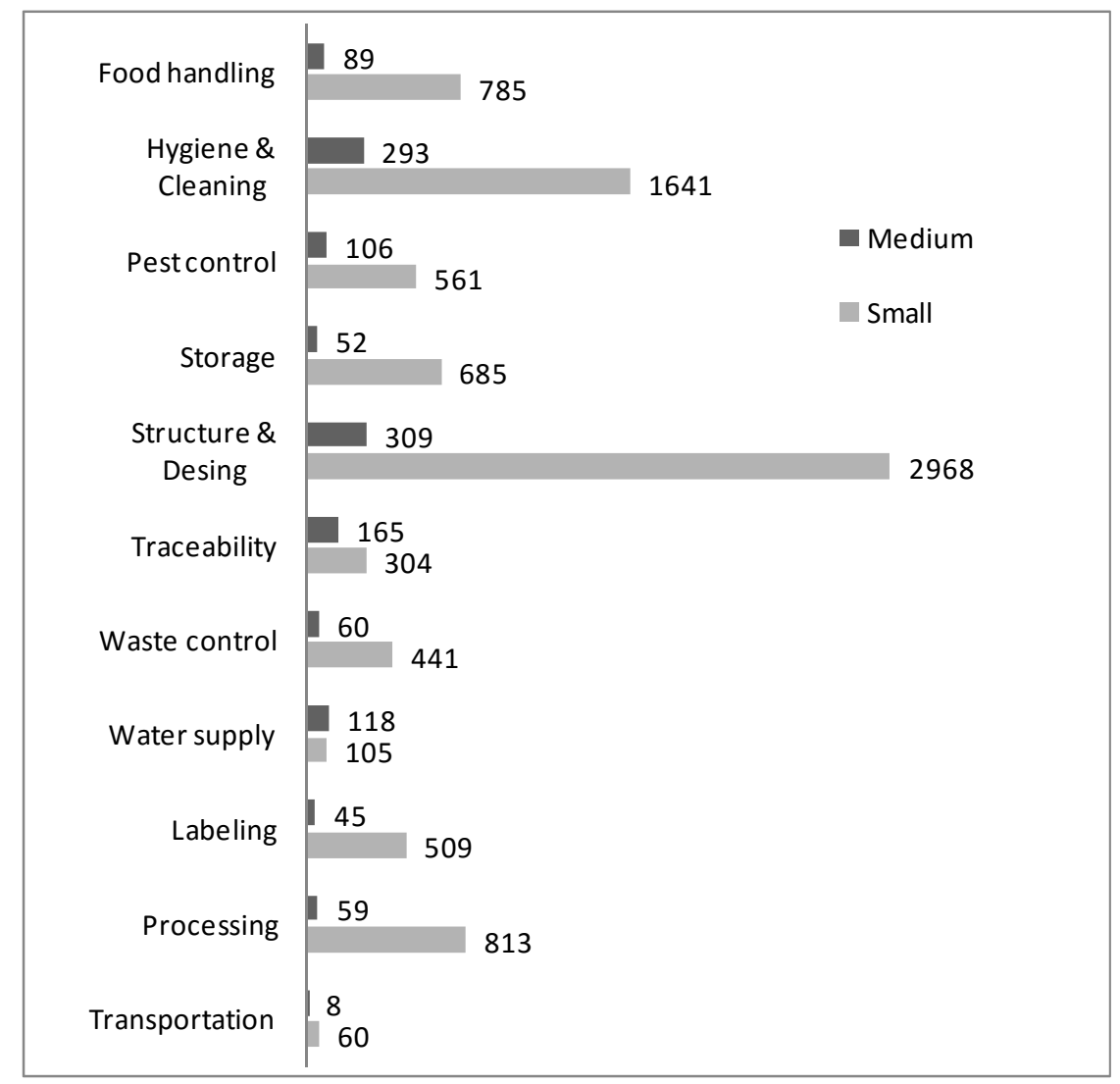

Fig. 2. Number of non-conformities detected in small and medium food establishments in relation to the inspected item

Table 1. Prevalence of L. monocytogenes with respect the groups of dishes (meat and fish)

\begin{tabular}{|c|c|c|c|c|c|c|}
\hline $\begin{array}{l}\text { Main course } \\
\text { type }\end{array}$ & No. samples & $\begin{array}{l}\text { Absence in } \\
25 \mathrm{~g} \text { No. }(*)\end{array}$ & $\begin{array}{l}\text { Presence in } \\
25 \mathrm{~g} \mathrm{No.}(\%) \\
\text { of samples }\end{array}$ & $\begin{array}{l}\text { No samples } \\
10-99 \\
\text { CFU/g }\end{array}$ & $\begin{array}{l}\text { No samples } \\
100-999 \\
\text { CFU/g }\end{array}$ & $\begin{array}{l}\text { No samples } \\
\geq 1000 \\
\text { CFU/g }\end{array}$ \\
\hline Meat & 814 & & & & & \\
\hline Minced meat & 226 & & & & & \\
\hline Meat ball & 114 & $56(49,12)$ & $58(50,88)$ & 58 & 0 & 0 \\
\hline Hamburgers & 112 & $59(52,68)$ & $53(47,32)$ & 53 & 0 & 0 \\
\hline $\begin{array}{l}\text { Non minced } \\
\text { meat }\end{array}$ & 588 & & & & & \\
\hline Pork & 290 & $215(74,14)$ & $75(25,86)$ & 71 & 4 & 0 \\
\hline Chicken & 203 & $149(73,40)$ & $54(26,60)$ & 54 & 0 & 0 \\
\hline Beef & 95 & $67(70,53)$ & $28(29,47)$ & 28 & 0 & 0 \\
\hline Fish & 247 & & & & & \\
\hline hake & 101 & $57(56.44)$ & $44(43.56)$ & 44 & 0 & 0 \\
\hline panga & 36 & $29(80.56)$ & $7(19.44)$ & 7 & 0 & 0 \\
\hline cod & 31 & $26(83.87)$ & $5(16.13)$ & 5 & 0 & 0 \\
\hline monkfish & 26 & $11(42.31)$ & $15(57.69)$ & 15 & 0 & 0 \\
\hline squid & 17 & $8(47.06)$ & $9(52,94)$ & 9 & 0 & 0 \\
\hline tuna & 13 & $9(69.23)$ & $4(30,77)$ & 4 & 0 & 0 \\
\hline gilthead & 10 & $8(80.00)$ & $2(20,00)$ & 2 & 0 & 0 \\
\hline swordfish & 7 & $6(85.71)$ & $1(14,29)$ & 1 & 0 & 0 \\
\hline sole & 6 & $5(83.33)$ & $1(16,67)$ & 1 & 0 & 0 \\
\hline
\end{tabular}

No. (\%) of samples 